\title{
Containerless Solidification and Net Shaping by Splat Quenching of Undercooled $\mathrm{Nd}_{2} \mathrm{Fe}_{14} \mathrm{~B}$ Melts
}

\author{
Kosuke Nagashio ${ }^{1, * 1}$, Mingjun $\mathrm{Li}^{1}$ and Kazuhiko Kuribayashi ${ }^{1,2, * 2}$ \\ ${ }^{1}$ The Institute of Space and Astronautical Science, Sagamihara 229-8510, Japan \\ ${ }^{2}$ CREST, Japan Science and Technology Corporation, Tsukuba 305-0047, Japan
}

\begin{abstract}
High-speed optical temperature measurement and digital imaging elucidated the solidification behavior of undercooled $\mathrm{Nd}_{2} \mathrm{Fe}_{14} \mathrm{~B}$ melt through containerless processing by an electromagnetic levitation method. The Fe phase solidified primarily from the melt. Subsequently, the remaining melt was undercooled below the peritectic temperature and the $\mathrm{Nd}_{2} \mathrm{Fe}_{14} \mathrm{~B}$ phase surrounded the primary Fe dendrites, yielding the recalescence. The clear interface of the thermal field propagated and covered the entire sample. Detailed microstructural observation showed that the $\mathrm{Nd}_{2} \mathrm{Fe}_{14} \mathrm{~B}$ phase surrounding the different Fe dendrites mutually came into contact with the several points. This suggested that many sites for nucleation of the $\mathrm{Nd}_{2} \mathrm{Fe}_{14} \mathrm{~B}$ phase are not necessary for the successive growth of the $\mathrm{Nd}_{2} \mathrm{Fe}_{14} \mathrm{~B}$ phase that was maintained by the spread of the $\mathrm{Nd}_{2} \mathrm{Fe}_{14} \mathrm{~B}$ phase to the different primary Fe dendrites. This resulted in the macroscopic interface of the thermal field during recalescence. Moreover, the undercooled melt was dropped from the levitation coil and quenched by a pair of copper chill plates with moulds, the shape of which is a hemisphere cap, in order to obtain a small bulk sample for industrial purpose. The spherical sample with the diameter of 5 mm was successively obtained without decreasing the cooling rate. This result suggests the possibility of the net shaping of a small magnet from the melt.
\end{abstract}

(Received November 18, 2002; Accepted April 4, 2003)

Keywords: containerless solidification, $\mathrm{Nd}_{2} \mathrm{Fe}_{14} \mathrm{~B}$, splat quench, peritectic reaction, net shaping

\section{Introduction}

Rapid solidification processing has been applied to improve the magnetic properties of $\mathrm{Nd}-\mathrm{Fe}-\mathrm{B}$ alloys. The electromagnetic-levitation (EML) method was used by Hermann and Loeser ${ }^{1)}$ fourteen years after Croat et al. obtained the energy product of 14 MGOe by a melt spinning technique. ${ }^{2)}$ As shown in 1989 by Yamamoto et al. ${ }^{3)}$ the fine spherical $\mathrm{Nd}-\mathrm{Fe}-\mathrm{B}$ powders produced by a high-pressure argon atomization technique resulted in a lower coercivity than that obtained via the melt spinning technique. The reason why there are limited investigations using the EML method may be in relatively lower cooling rate than that of the atomization technique. However, it is difficult to reveal the rapid solidification behavior during the melt spinning and atomization because of the difficulty of the temperature measurement during quenching and solidification, while the containerless processing allows us to observe the solidification behavior owing to the free surface of a levitated sample with measurable size. Therefore, in situ observation via a high-speed video camera (HSV) is beneficial for revealing what actually occurred during the rapid solidification.

Recently, small permanent magnets of millimeter size have been desired for the control of electric and optical devices $^{4)}$ and are cut from large ingots prepared by bond magnets or sintered magnets. Considering the cutting loss, the introduction of the net-shaping technique which enables the direct formation of the magnet with desired shape from the melt is required. Here, EML was combined with the splatquenching system to increase the cooling rate. The undercooled melt was dropped from the levitation coil and quenched by a pair of copper chill plates with moulds, the shape of which is the hemisphere cap, to obtain the small

\footnotetext{
${ }^{* 1}$ Present address, Center for Materials Research, Stanford University, Stanford, CA 94305-4045, USA.

${ }^{* 2}$ Corresponding author: kuribayashi@materials.isas.ac.jp
}

permanent magnet directly. The objective in this study is to explore the possibility of the net shaping of a small magnet from the melt as well as to observe the rapid solidification behavior using the HSV.

\section{Experimental}

Figure 1 shows a schematic of the EML apparatus with the splat-quenching system. The ingot with stoichiometric $\mathrm{Nd}_{2} \mathrm{Fe}_{14} \mathrm{~B}$ composition prepared by arc melting was cut into small pieces by a diamond cutter. Several samples were placed on quartz sample holders in a chamber. The chamber was then evacuated to around $10^{-3} \mathrm{~Pa}$ and backfilled by highpurity $\operatorname{Ar}$ gas $(6 \mathrm{~N})$. The sample was levitated and melted by the electromagnetic force of a coil and then cooled by a flow of high-purity He gas $(6 \mathrm{~N})$ from the bottom of the droplet so that the sample could solidify at the levitation state. The temperature of the melt surface was monitored at $100 \mathrm{~Hz}$ with a two-color pyrometer with central operating wavelengths of

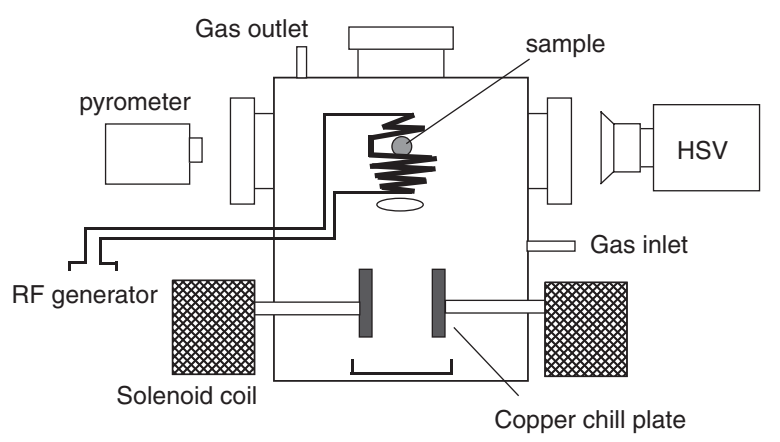

Fig. 1 Schematic of the EML combined with direct current-driven splat quenching apparatus. The distance from the levitation center in the coil to the center of the chill plates is $200 \mathrm{~mm}$. The quenching is adjusted by varying the delay time between the release of the droplet and start of the chill plates. 
0.9 and $1.55 \mu \mathrm{m}$ and a spot diameter of $1 \mathrm{~mm}$. Moreover, a color high-speed video camera (HSV) with the high resolution of $572 \times 434$ pixels, NAC MEMRECAM Ci-4, was operated at 500 frames/s to observe the solidification behavior during cooling.

Alternatively, the levitated sample was released by turning off the main power of the levitation coil, which triggered a pair of direct current-driven solenoids with a variable delay time system. The solenoids quickly moved the copper chill plate. In the present experiment, two types of chill plates were used, a flat type and a mould type. The mould type has a 5-mm-diameter hemisphere cap machined at the center of the plate. The resulting shape of the quenched sample is a thin disk or spherical shape, depending on respectively, whether a flat or mould type chill plate is used. The processed specimens were analyzed by scanning electron microscopy (SEM) in conjunction with an energy-dispersive spectroscope (EDS) and powder X-ray diffraction (XRD) method.

\section{Results}

Figure 2(a) shows the XRD result for the sample nucleated spontaneously in the EML. The intense peak of the Fe phase was observed and the $\mathrm{Nd}_{2} \mathrm{Fe}_{14} \mathrm{~B}$ phase was also identified.

Figure 3 shows the cross-sectional micrograph of the sample nucleated spontaneously in the EML. The black, gray and white parts are the $\mathrm{Fe}, \mathrm{Nd}_{2} \mathrm{Fe}_{14} \mathrm{~B}$ and Nd-enriched phases, respectively, which were confirmed by the comparison of the EDS and XRD results. The dendritic Fe phase solidified primarily and was surrounded by the $\mathrm{Nd}_{2} \mathrm{Fe}_{14} \mathrm{~B}$ phase. The $\mathrm{Fe}$ dendrites (A) and (B) seem to grow from different nuclei because they exhibit different growth directions. The $\mathrm{Nd}_{2} \mathrm{Fe}_{14} \mathrm{~B}$ phase which surrounded the $\mathrm{Fe}$ dendrites (A) and (B), however, came into contact with each other at several points, though segregation of the $\mathrm{Nd}$-enriched phase was mainly observed between $\mathrm{Nd}_{2} \mathrm{Fe}_{14} \mathrm{~B}$ phases. This

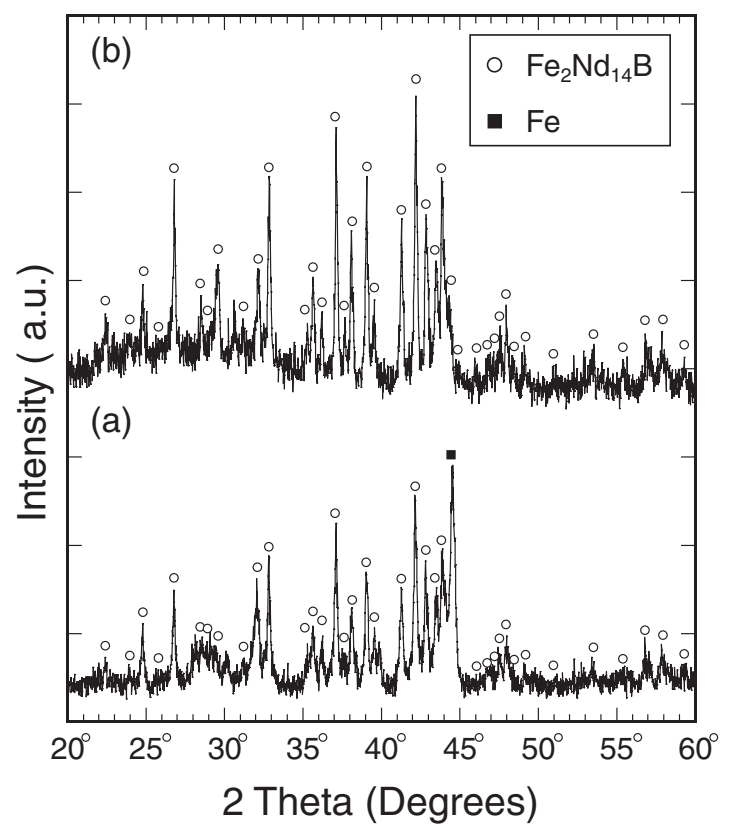

Fig. 2 XRD patterns for the spontaneously nucleated sample (a) and the sample dropped at $1605 \mathrm{~K}$ and quenched by the copper chill plates (b).

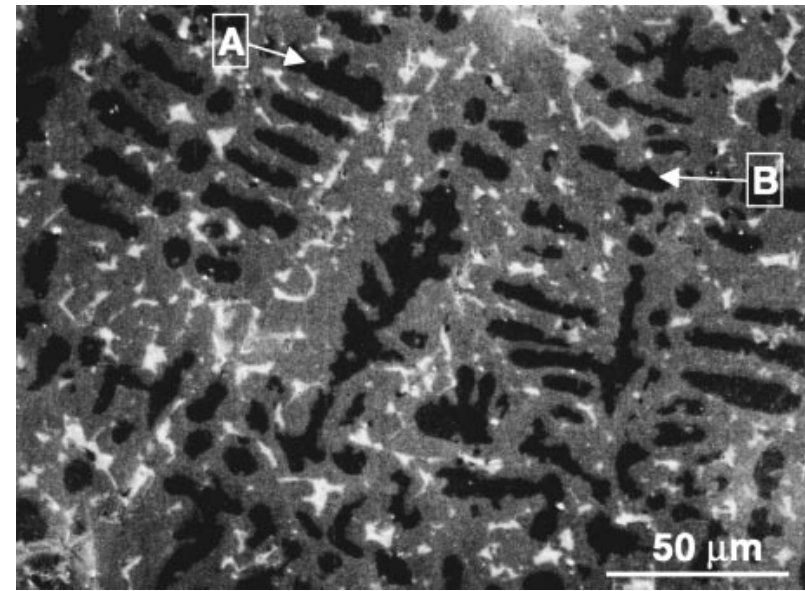

Fig. 3 Cross-sectional SEM micrograph of the spontaneously nucleated sample. The dark and brown phases are the $\mathrm{Fe}$ and $\mathrm{Nd}_{2} \mathrm{Fe}_{14} \mathrm{~B}$ phases, respectively. The $\mathrm{Nd}$ enriched phase was observed between the $\mathrm{Nd}_{2} \mathrm{Fe}_{14} \mathrm{~B}$ phases.

microstructure was observed throughout the sample.

Figure 4 shows the cooling curves measured by the twocolor pyrometer. The curves (a) and (b) were raw data obtained by $\mathrm{Si}(0.9 \mu \mathrm{m})$ and $\mathrm{InGaAs}(1.55 \mu \mathrm{m})$ detectors with the emissivity $(\varepsilon)$ of unity, respectively. Here, the surface temperature (c) was calculated by the two-color calibration based on the assumption that the $\varepsilon$ value at $0.9 \mu \mathrm{m}$ is the same as that at $1.55 \mu \mathrm{m}$. The result, however, is unreasonable because according to the equilibrium phase diagram of $\mathrm{Fe}-$ $\mathrm{Nd}-\mathrm{B}$ there is no phase change at the temperature where the first recalescence was observed and the post-recalescence temperature of the second one is higher than the liquidus temperature $T_{\mathrm{L}}$.

Figure 5 shows the sequential HSV images that correspond to the first recalescence in Fig. 4(c). Each frame is taken at intervals of $0.03 \mathrm{~s}$. The small bright particles initially appeared near the bottom of the sample, then coalesced at the top part of the droplet. Finally the formed surface layer spread downward. This layer should be suspected to an oxide film. Since the oxidation of the sample and formation of a thin film do not release sufficient heat so as to elevate the temperature high enough so that it can be measured by a pyrometer, the first recalescence can be regarded as unreal but apparent. The $\varepsilon$ value of an oxide is larger than that of a metallic material. This means the brightness of the oxide is greater than that of the metallic material, even if their temperatures are similar. In addition, the first recalescence in the cooling curve (b) is not as clear as that in (a). The reason for this is that the InGaAs detector is insensitive to the formation of the thin film because the operating wavelength is nearly equal to or larger than the thickness of the thin film. In this case, it can be concluded qualitatively that the InGaAs detector monitors the inside of the oxide film, whereas the $\mathrm{Si}$ detector monitors the surface of the film. In fact, the $\varepsilon$ value evaluated through the two-color calibration changed to 0.11 as the surface film was formed, as shown in Fig. 4(d). The theoretical basis of the two-color calibration failed completely here. Therefore, the actual surface temperature (e) was calibrated from the cooling curve (b) using the constant value of $\varepsilon=0.20$, which was evaluated through the two-color 


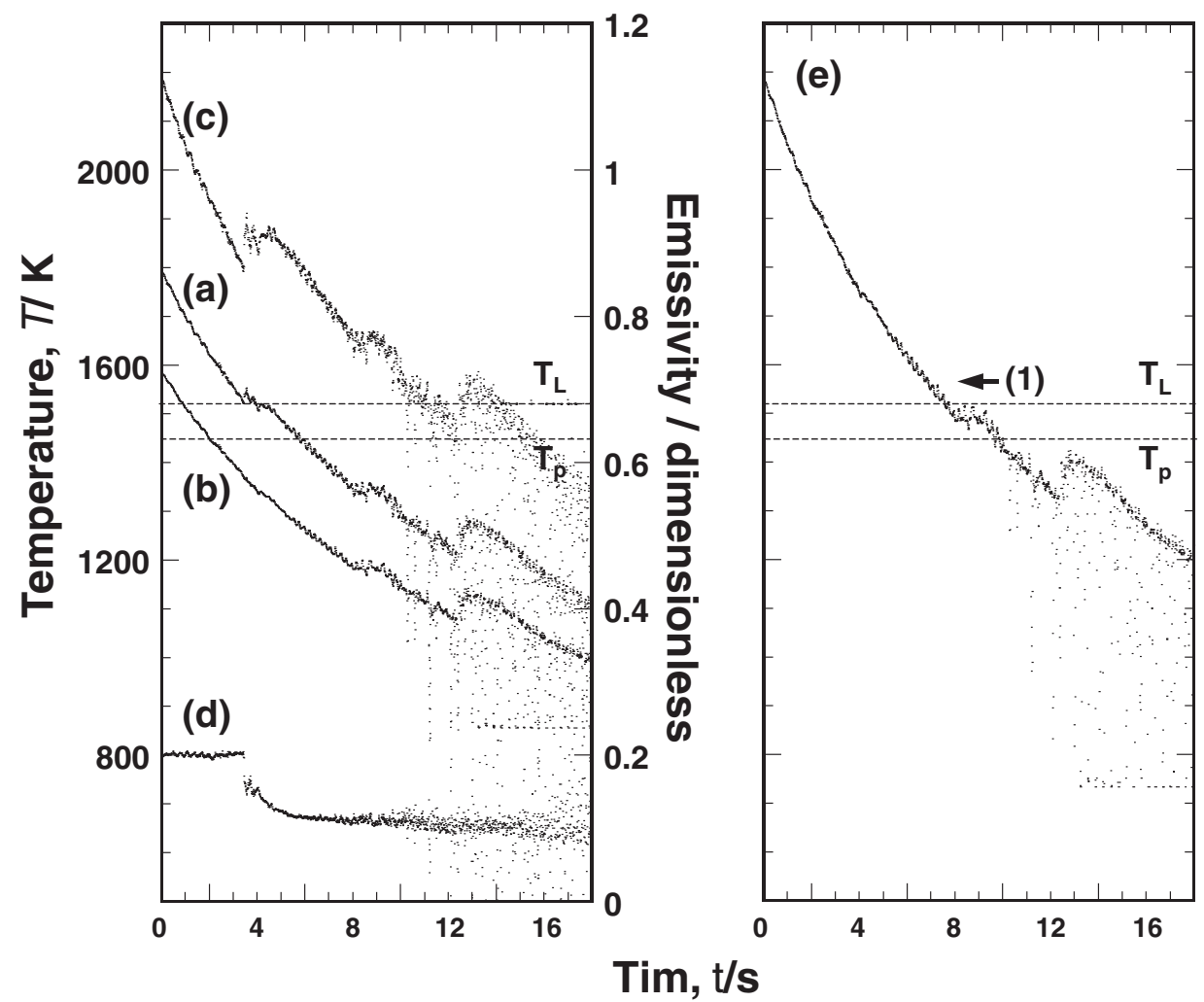

Fig. 4 Typical cooling curves measured by the two-color pyrometer with $\mathrm{Si}(0.9 \mu \mathrm{m})$ and InGaAs $(1.55 \mu \mathrm{m})$ detectors. (a) By Si with $\varepsilon=1$, (b) by InGaAs with $\varepsilon=1$, (c) by two-color calibration independent of the $\varepsilon$ value, (d) emissivity change as a function of time, and (e) by InGaAs with constant value of $\varepsilon=0.20 . T_{\mathrm{L}}$ and $T_{\mathrm{P}}$ indicate the liquidus temperature and the peritectic temperature, respectively.

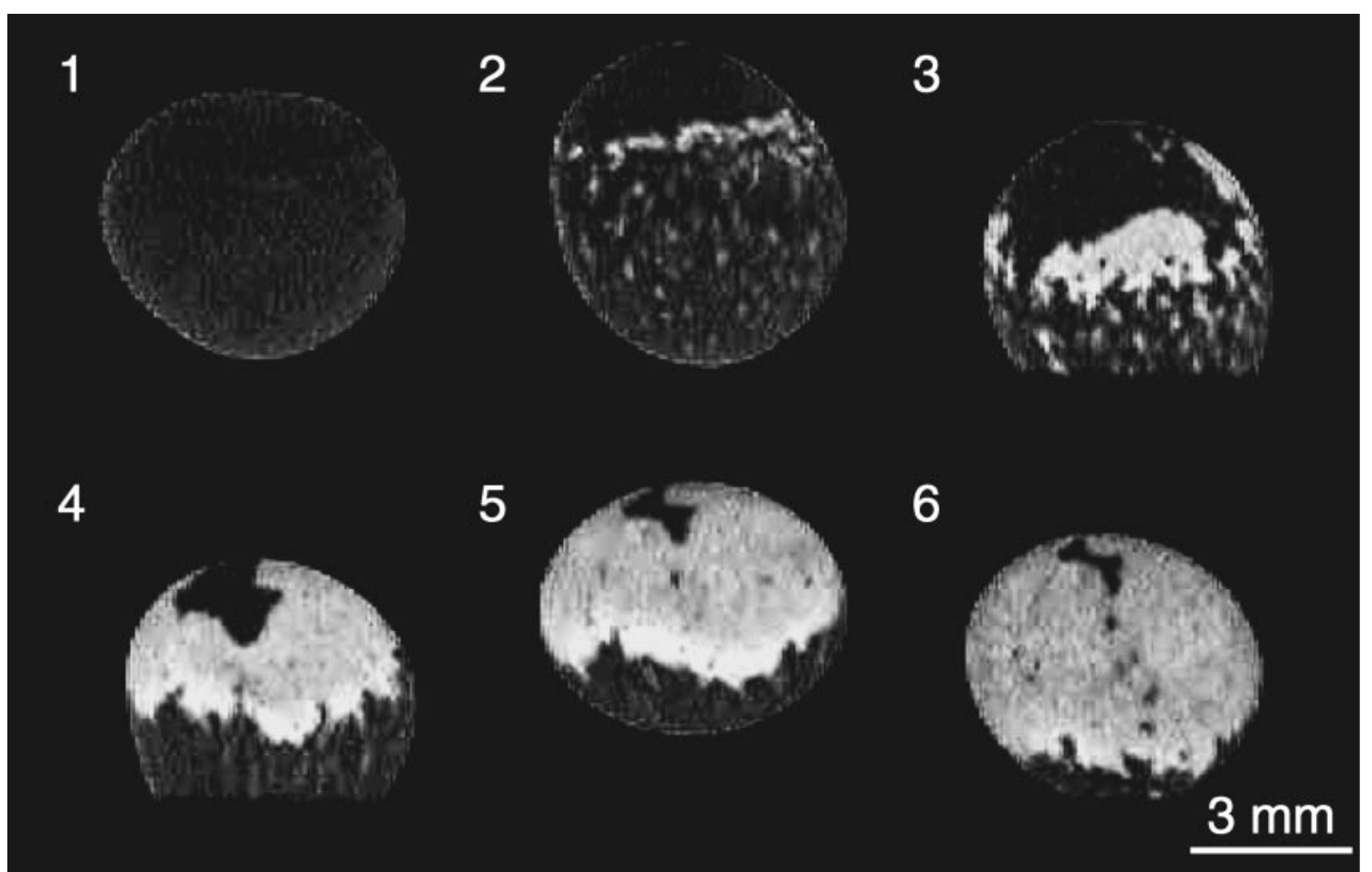

Fig. 5 First recalescence behavior captured by the HSV. Frames are shown at intervals of $0.03 \mathrm{~s}$. The bright particles were blown up from the bottom and the thin layer was formed. 


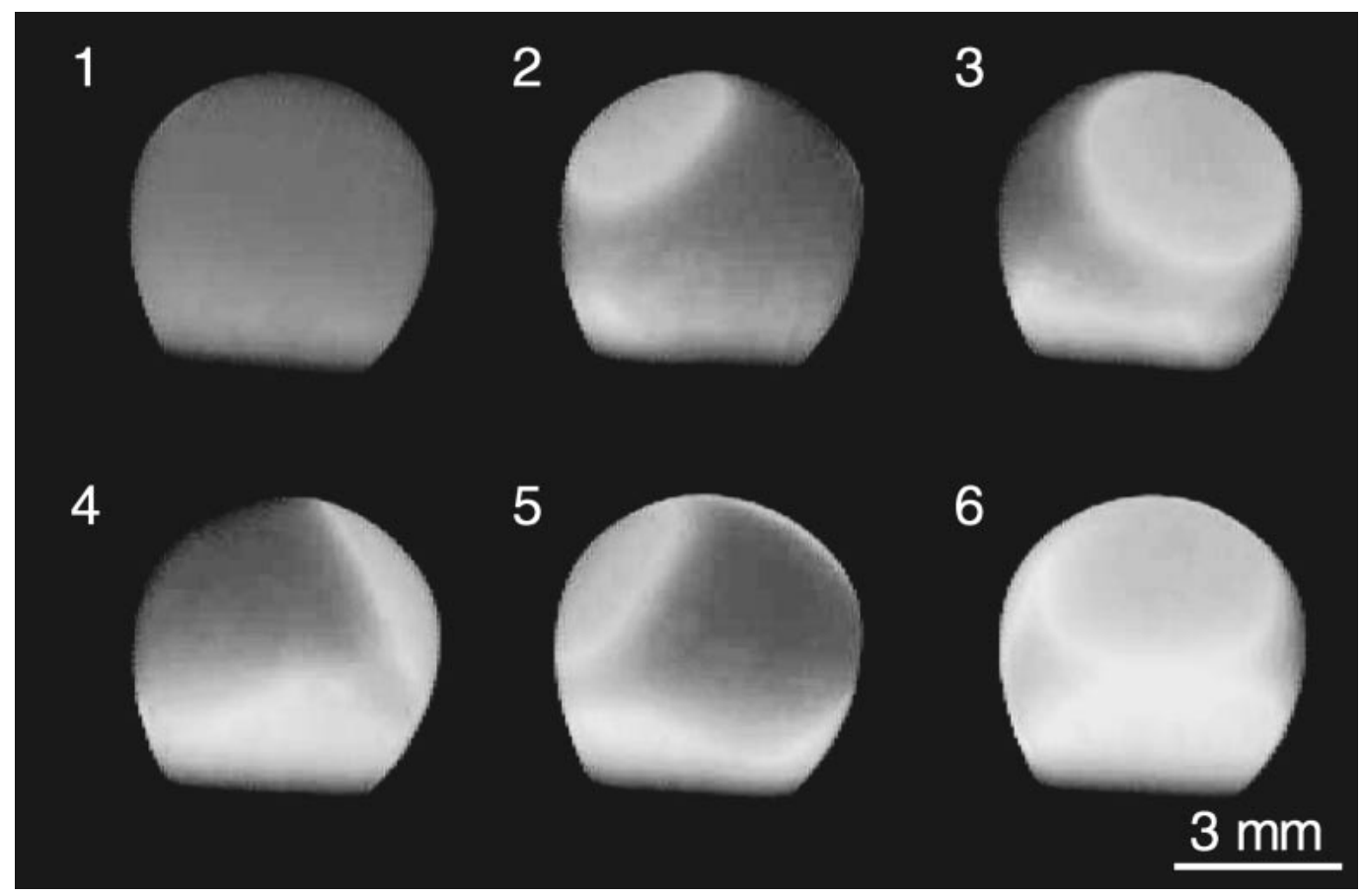

Fig. 6 Third recalescence behavior captured by the HSV. Frames are shown at intervals of $0.08 \mathrm{~s}$. The dark part was the mixture of the primary Fe phase and remaining liquid, while the bright part was the thermal field produced by the peritectic reaction of the Fe and liquid phases, which were observed through the thin layer. The sample was rotating during recalescence.

calibration above the temperature where the oxide film appears. The result is that the post-recalescence temperature was corrected to be below the liquidus temperature.

From the microstructural observation in Fig. 3, therefore, the second recalescence and the third recalescence were ascribed to the solidification of the primary $\mathrm{Fe}$ and $\mathrm{Nd}_{2} \mathrm{Fe}_{14} \mathrm{~B}$ phases, respectively.

Figure 6 shows the sequential HSV images that correspond to the third recalescence. Each frame was taken at intervals of $0.08 \mathrm{~s}$. It is clear that the interface of the thermal field propagates and completes the sample.

In order for the growth kinetics of the peritectic $\mathrm{Nd}_{2} \mathrm{Fe}_{14} \mathrm{~B}$ phase to be dominated, the levitated melt was released at the predetermined temperature by turning off the RF power in the levitation coil and quenched by pressing the droplet from both sides between a pair of copper plates, as shown in Fig. 1. The quenching temperature is just above the temperature where the primary Fe phase nucleates, as shown by the arrow (1) in Fig. 4(e). Figure 7 shows the SEM micrograph of the cross-sectional plane of the splat-quenched sample, where arrows indicate the direction of quenching. The typical thickness of the quenched sample was $100 \mu \mathrm{m}$. The crosssectional plane was etched by $3 \% \mathrm{HNO}_{3}$ solution after polishing and the microstructure was revealed. No phase other than the $\mathrm{Nd}_{2} \mathrm{Fe}_{14} \mathrm{~B}$ phase was identified by the XRD analysis, as shown in Fig. 2(b). The grain size of the $\mathrm{Nd}_{2} \mathrm{Fe}_{14} \mathrm{~B}$ phase measured at the quenched surface is too small to be qualified by the SEM micrograph, whereas it is $5 \mu \mathrm{m}$ at the midpoint of thickness.

Moreover, the undercooled melt was quenched by a pair of copper chill plates with moulds, the shape of which is a hemisphere cap in order to obtain a small bulk sample. Figure 8 shows the whole view of (a) the sample solidified under levitation and (b) the sample splat-quenched by a pair

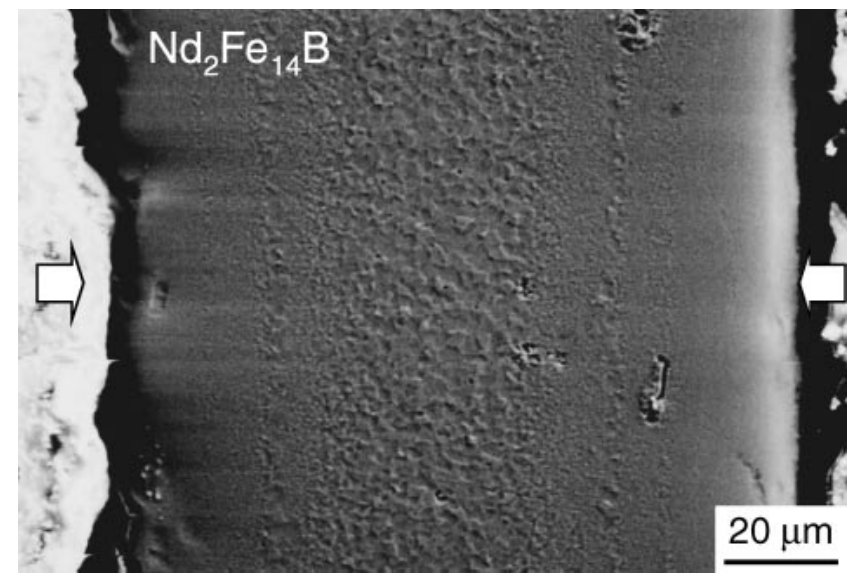

Fig. 7 Cross-sectional SEM micrographs of the sample dropped and splat quenched at $1590 \mathrm{~K}$. The arrows indicate the quenching direction. This sample was etched by $3 \% \mathrm{HNO}_{3}$ solution for 20 seconds.
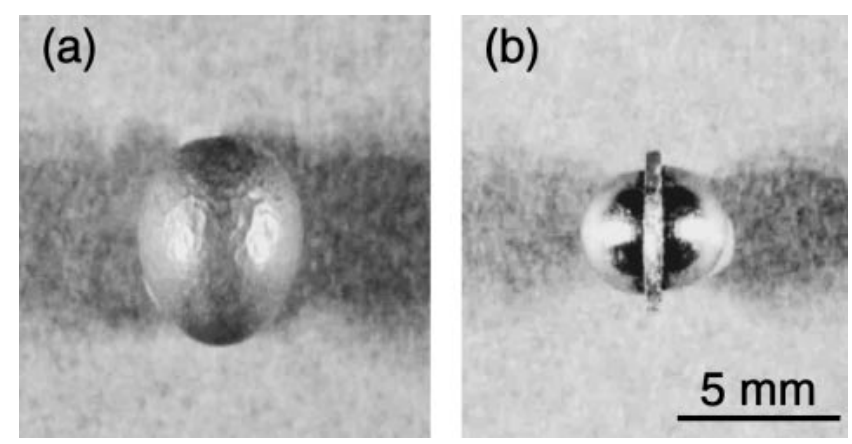

Fig. 8 Appearance of the sample solidified in the levitation coil (a) and quenched by copper chill plates with hemispherical holes (b). The diameter is almost the same, while the cooling rate for quenched sample is much higher than that for the sample solidified in the coil. 

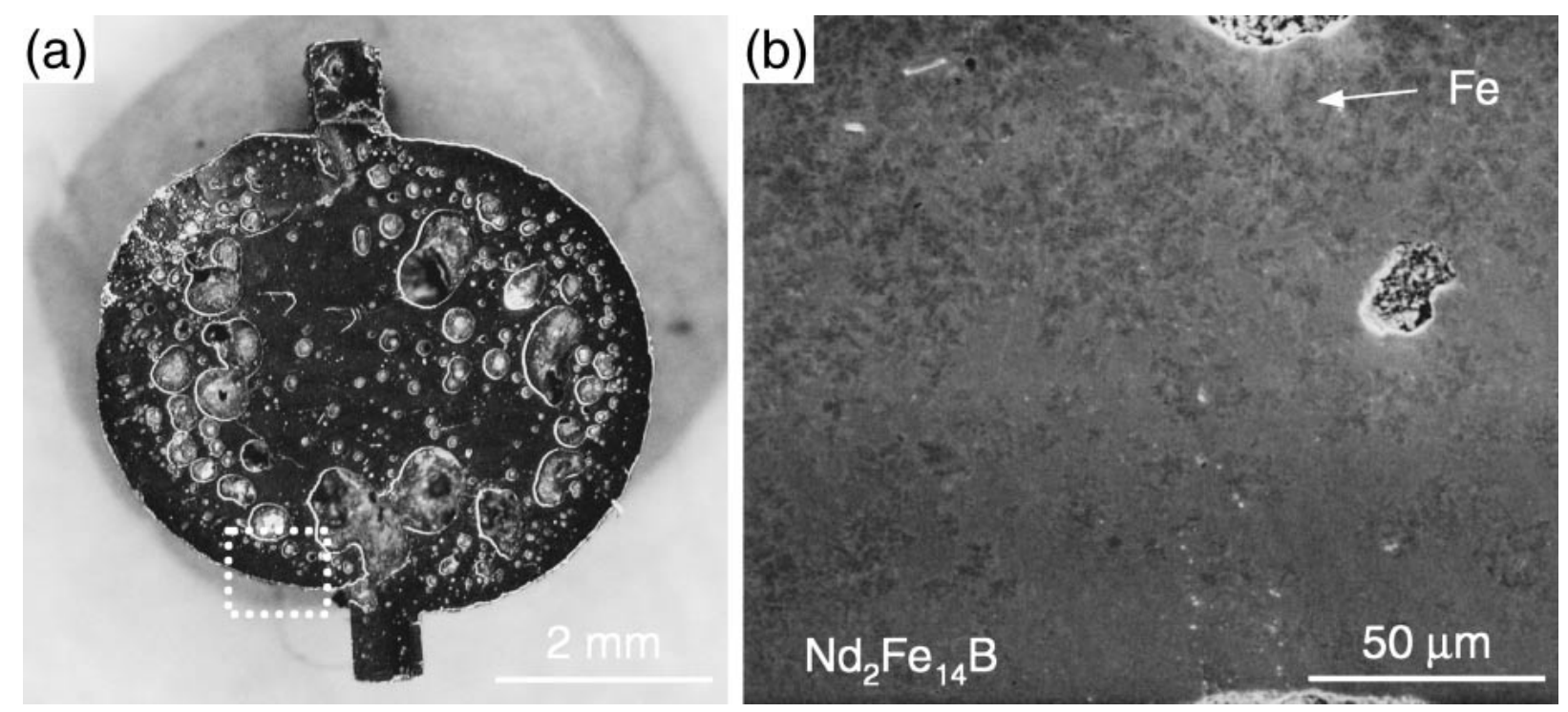

Fig. 9 Cross-sectional micrographs of the sample quenched by copper chill plates with hemispherical holes. (a) The whole image taken by stereomicroscope, (b) the magnified SEM image in the white dotted box of (a).

of copper chill plates with moulds of a hemispherical cap. It is clear that the sample quenched by chill plates has the same shape as that of the mould. Figure 9(a) shows a crosssectional micrograph of the sample quenched by chill plates, which is taken by a stereomicroscope. Numerous voids are observed with diameters of $10-800 \mu \mathrm{m}$ inside the sample. This may be because the Ar gas in the mould was involved into the sample during quenching. It can be thought that the backfilled gas trapped inside the moulds during quenching formed these voids. The magnified SEM image of the white dotted square in Fig. 9(a) is shown in Fig. 9(b). As shown in this figure, the $\mathrm{Nd}_{2} \mathrm{Fe}_{14} \mathrm{~B}$ phase is predominant at the edge part, while equi-axed grains of the Fe phase are seen to have grown in the area far from the edge part, particularly at the center.

\section{Discussion}

The high undercooling $\sim 300 \mathrm{~K}$ of Fe alloys such as $\mathrm{Fe}-\mathrm{P}^{5)}$ and $\mathrm{Fe}-\mathrm{Ni}^{6}$ has been reported using the EML. In the present study, however, the undercooling level of the melt was much lower than the Fe alloys, as shown in Fig. 4(e), because the thin film formed at temperatures above the liquidus temperature during cooling catalyzed the nucleation of the primary Fe phase. This thin film appears to be an oxide. Sellers et al. ${ }^{7)}$ identified the thin film of the $\mathrm{Nd}_{2} \mathrm{O}_{3}$ phase on the atomization powders by Auger analysis. However, it appears that the present thin film is not of the $\mathrm{Nd}_{2} \mathrm{O}_{3}$ phase but of the ternary $\mathrm{Fe}-\mathrm{Nd}-\mathrm{O}$ phase where the activity of $\mathrm{Nd}$ is markedly reduced, because this layer diminished at temperatures of more than $1900 \mathrm{~K}$ under levitation, which is much lower than the melting point of the $\mathrm{Nd}_{2} \mathrm{O}_{3}$ phase $\left(\sim 2300 \mathrm{~K}^{8)}\right)$.

Three mechanisms for the formation of the peritectic phase have been reviewed. ${ }^{9)}$ First, the primary phase decomposes at the triple junction of primary, peritectic and liquid phases and solute atoms are incorporated into the peritectic phase through liquid-state diffusion. This is the peritectic reaction. Second, solute atoms are incorporated into the peritectic phase through solid-state diffusion. This is defined as the peritectic transformation. Finally, the direct growth occurs from the liquid whose chemical composition is close to the peritectic liquid composition. Note that this direct growth is different from the primary growth of the peritectic phase from the undercooled melt. ${ }^{10,11)}$ St John and Hogan ${ }^{12)}$ reported typical cooling curves in the peritectic $\mathrm{Zn}-8 \mathrm{wt} \% \mathrm{Cu}$ alloy at different cooling rates. They showed that the duration of the plateau at the peritectic temperature decreased with increasing cooling rates and finally disappeared. They suggested, based on this experimental result, that the peritectic transformation corresponding to the duration of the plateau was suppressed as the cooling rate was increased, because the peritectic reaction is so fast that the small amount of solid formed during the reaction is not expected to release sufficient latent heat for the temperature to be constant at the equilibrium temperature. In the $\mathrm{Fe}-\mathrm{Nd}-\mathrm{B}$ system, however, clear recalescence was observed, as shown in Figs. 4(e) and 6.

In the present $\mathrm{Fe}-\mathrm{Nd}-\mathrm{B}$ system, detectable undercooling $\sim 100 \mathrm{~K}$ of the $\mathrm{Nd}_{2} \mathrm{Fe}_{14} \mathrm{~B}$ phase from the peritectic temperature indicates that the primary $\mathrm{Fe}$ phase as well as the thin film formed on the surface do not have sufficient catalytic potential for the $\mathrm{Nd}_{2} \mathrm{Fe}_{14} \mathrm{~B}$ phase to be nucleated heterogeneously, in contrast with the $\mathrm{Zn}-\mathrm{Cu}$ alloy system. Moreover, it is difficult for the peritectic transformation to occur after the primary Fe phase is surrounded by the $\mathrm{Nd}_{2} \mathrm{Fe}_{14} \mathrm{~B}$ phase, because the $\mathrm{Nd}_{2} \mathrm{Fe}_{14} \mathrm{~B}$ phase is a stoichiometric compound in which there is no compositional gradient. Therefore, the peritectic reaction and the direct growth are the predominant sources of the rapid heat release corresponding to the pronounced recalescence. Hence, a clear macroscopic interface formed by the thermal field was observed as shown in Fig. 6. Figure 10 illustrates possible growth modes of the $\mathrm{Nd}_{2} \mathrm{Fe}_{14} \mathrm{~B}$ phase during recalescence. If the $\mathrm{Nd}_{2} \mathrm{Fe}_{14} \mathrm{~B}$ phase can grow from one nucleation site independent of the primary Fe dendrites (a), the macroscopic interface shown in Fig. 6 should be observed. However, the 


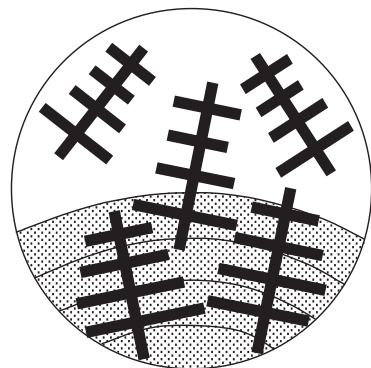

(a)

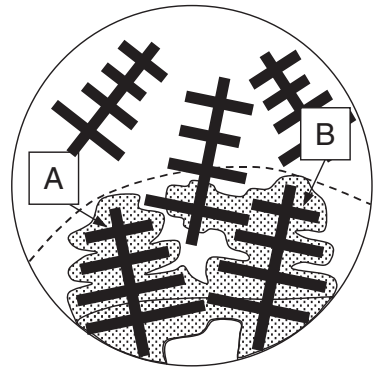

(b)

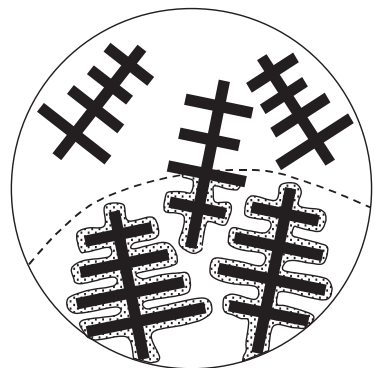

(c)

Fig. 10 Schematic of three possible growth modes of the $\mathrm{Nd}_{2} \mathrm{Fe}_{14} \mathrm{~B}$ phase during recalescence. The solid and broken lines indicate the macroscopic interface of the thermal field which will appear on the surface. (a) The growth of the $\mathrm{Nd}_{2} \mathrm{Fe}_{14} \mathrm{~B}$ phase is independent of the primary Fe dendrites. (b) The $\mathrm{Nd}_{2} \mathrm{Fe}_{14} \mathrm{~B}$ phase propagates using the network of the primary Fe dendrites mainly by the direct growth. (c) The $\mathrm{Nd}_{2} \mathrm{Fe}_{14} \mathrm{~B}$ phase grows mainly by the peritectic reaction. The nucleation of the $\mathrm{Nd}_{2} \mathrm{Fe}_{14} \mathrm{~B}$ phase is required on each primary $\mathrm{Fe}$ dendrite for successive growth.

microstructure in Fig. 3 indicates that the growth mode (b) is plausible and that the $\mathrm{Nd}_{2} \mathrm{Fe}_{14} \mathrm{~B}$ phase surrounding the $\mathrm{Fe}$ dendrite (A) came into contact with the other $\mathrm{Nd}_{2} \mathrm{Fe}_{14} \mathrm{~B}$ phase surrounding the $\mathrm{Fe}$ dendrite $(\mathrm{B})$. In this case, one nucleus of the $\mathrm{Nd}_{2} \mathrm{Fe}_{14} \mathrm{~B}$ phase is sufficient for successive growth and the recalescence interface to appear macroscopically as shown by the broken line in Fig. 10(b). At growth mode (c), many sites of nucleation are allowed. However, successive nucleation to lead to the macroscopic interface during recalescence is not appreciated because nucleation is expected to occur at any sites on the sample surface. In order that the $\mathrm{Nd}_{2} \mathrm{Fe}_{14} \mathrm{~B}$ phase surrounding different Fe dendrites can come into contact with each other, the direct growth must be more predominant than the peritectic reaction during recalescence. This is also supported by the fact that the volume fraction of the $\mathrm{Nd}_{2} \mathrm{Fe}_{14} \mathrm{~B}$ phase is larger than that expected only by the peritectic reaction. In fact, St John ${ }^{13}$ ) suggested that the direct growth of the peritectic phase is more likely to occur than the peritectic reaction in the $\mathrm{Cu}-\mathrm{Sn}$ alloys. He, however, has not clarified the mechanism for the direct growth.

Hitherto, the preferential synthesis of the $\mathrm{Nd}_{2} \mathrm{Fe}_{14} \mathrm{~B}$ phase to the Fe phase during melt spinning has been discussed based on the continuous-cooling transformation (CCT) diagram. ${ }^{14-16)}$ The CCT diagram focuses on nucleation rates in different phases at different cooling rates. Recently, Umeda et $a l .{ }^{17)}$ discussed phase selection from the viewpoint of the competitive growth in the peritectic system under directional solidification conditions based on interface response functions. ${ }^{18)}$ It was suggested that the $\mathrm{Nd}_{2} \mathrm{Fe}_{14} \mathrm{~B}$ phase should grow preferentially at the growth velocity higher than the critical velocity of $\sim 1 \mathrm{~mm} / \mathrm{s}$ where the transition from the $\mathrm{Fe}$ phase to the $\mathrm{Nd}_{2} \mathrm{Fe}_{14} \mathrm{~B}$ phase can occur. However, their theoretical calculation is not applicable to the present study because the variable parameter for the directional solidification is the interface undercooling, not the bulk undercooling which can be obtained experimentally in the containerless solidification. Here, the basic concept of phase selection under the free growth condition is that growth velocities of competitive phases are independently calculated at the same starting melt composition and compared on the basis that the phase with a higher growth velocity is predominant. Moreover, phase selection does not predict the growth behavior of the 2 nd phase accompanied with the growth of the predominant phase, because the growth conditions of both phases are taken into account for the melt with the same starting chemical composition. In the present study, therefore, the growth velocities of the $\mathrm{Fe}$ and $\mathrm{Nd}_{2} \mathrm{Fe}_{14} \mathrm{~B}$ phases were independently calculated as a function of undercooling using free dendrite growth model with the kinetic undercooling proposed by Lipton, et al. (LKT model $\left.^{19)}\right)$. The total undercooling $(\Delta T)$ for a single phase growth consists of four contributions:

$$
\Delta T=\Delta T_{\mathrm{c}}+\Delta T_{\mathrm{t}}+\Delta T_{\mathrm{r}}+\Delta T_{\mathrm{k}},
$$

where $\Delta T_{\mathrm{c}}$ is constitutional undercooling, $\Delta T_{\mathrm{t}}$ is thermal undercooling, $\Delta T_{\mathrm{r}}$ is curvature undercooling and $\Delta T_{\mathrm{k}}$ is kinetic undercooling. The relationship between $\Delta T$ and $V$ is obtained from the eq. (1) when marginal stability criteria ${ }^{20)}$ is applied.

Figure 11 shows the growth velocities of the $\mathrm{Fe}$ and $\mathrm{Nd}_{2} \mathrm{Fe}_{14} \mathrm{~B}$ phases as a function of the melt temperature. $T_{\mathrm{L}}$, $T_{\mathrm{C}}$ and $T_{\mathrm{P}}$ indicate the liquidus temperature, hypothetical congruent melting point and the peritectic temperature, respectively. The physical properties used in the calculation

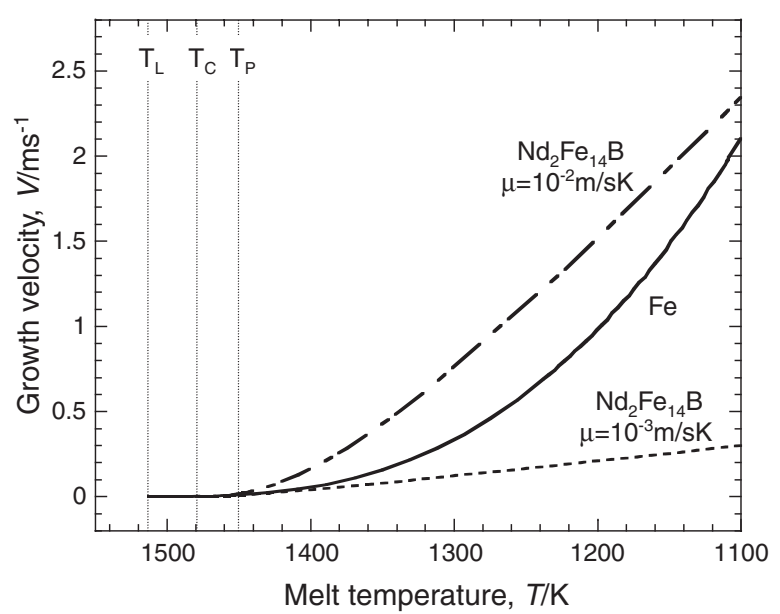

Fig. 11 Theoretical calculation of the growth velocities of the $\mathrm{Fe}$ and $\mathrm{Nd}_{2} \mathrm{Fe}_{14} \mathrm{~B}$ phases as a function of the melt temperature. $T_{\mathrm{c}}$ and $T_{\mathrm{p}}$ are the hypothetical congruent melting point and the peritectic temperature, respectively. 
Table 1 Physical properties ${ }^{17)}$ used for the theoretical calculation in Fig. 9. In this system, only the $\mathrm{Nd}$ atom was assumed to be solute in these properties, because the redistribution of the $\mathrm{B}$ atom at the solid/liquid interface will not restrict the growth of $\mathrm{Nd}_{2} \mathrm{Fe}_{14} \mathrm{~B}$ phase due to its interstitial type atom. ${ }^{17)}$

\begin{tabular}{clccc}
\hline \multicolumn{1}{c}{ Parameter } & Unit & $\mathrm{Fe}$ & $\mathrm{NdFeB}$ \\
\hline$C$ & Nd concentration & & 0 & 11.8 \\
$T_{\mathrm{L}}$ & Liquidus temperature & $\mathrm{K}$ & 1513 & - \\
$T_{\mathrm{p}}$ & Peritectic temperature & $\mathrm{K}$ & - & 1450 \\
$T_{\mathrm{c}}$ & Congruent melting point & $\mathrm{K}$ & - & 1480 \\
$m_{\mathrm{L}}$ & Liquidus slope & $\mathrm{K} / \mathrm{at} \%$ & -16.5 & -7.7 \\
$m_{\mathrm{S}}$ & Solidus slope & $\mathrm{K} / \mathrm{at} \%$ & - & - \\
$\Gamma$ & Gibbs-Thomson coefficient & $\mathrm{mK}$ & $2 \times 10^{-7}$ & $1 \times 10^{-6}$ \\
$\alpha_{\mathrm{L}}$ & Thermal diffusivity & $\mathrm{m}^{2} / \mathrm{s}$ & $6.1 \times 10^{-6}$ & $6.1 \times 10^{-6}$ \\
$\rho$ & Density & $\mathrm{mol} / \mathrm{m}^{3}$ & $1.3 \times 10^{5}$ & $1.76 \times 10^{3}$ \\
$k_{\mathrm{s}}$ & Thermal conductivity & $\mathrm{W} / \mathrm{mK}^{2}$ & 33 & 20 \\
$D$ & Diffusion coefficient in liquid & $\mathrm{m}^{2} / \mathrm{s}$ & $5 \times 10^{-9}$ & $5 \times 10^{-9}$ \\
$\Delta H_{\mathrm{f}}$ & Latent heat & $\mathrm{J} / \mathrm{m}^{3}$ & $1.93 \times 10^{9}$ & - \\
$c_{\mathrm{p}}$ & Heat capacity & $\mathrm{J} / \mathrm{m}^{3} \mathrm{~K}$ & $5.74 \times 10^{6}$ & - \\
$\Delta T_{\text {hyp }}$ & Hypercooling limit & $\mathrm{K}$ & 336 & $518\left(0.35 T_{\mathrm{M}}\right)$ \\
$\mu$ & Kinetic coefficient & $\mathrm{m} / \mathrm{sK}^{2}$ & 2 & - \\
\hline
\end{tabular}

are listed in Table 1. The hypercooling limit, $\left(\Delta T_{\mathrm{hyp}}=\right.$ $\left.\Delta H_{\mathrm{f}} / C_{\mathrm{P}}^{\mathrm{L}}\right)$ and the linear kinetic coefficient $(\mu)$ for the $\mathrm{Nd}_{2} \mathrm{Fe}_{14} \mathrm{~B}$ phase are yet unknown. It was assumed in the calculation that $\Delta T_{\text {hyp }}=0.35 T_{\mathrm{M}}$, because this value is typical in metallic materials and the hypercooling limit is not the parameter that can control the growth velocity. On the other hand, $\mu$ is the most important parameter especially for materials with high entropy of fusion, given as follows,

$$
\Delta T_{\mathrm{k}}=\frac{V}{\mu} .
$$

The small $\mu$ value leads to the low growth velocity at the constant $\Delta T$. Generally, $\mu$ is on the order of $1,10^{-1}$ and $10^{-2}$ for metals, semiconductors and intermetallic compounds, respectively. ${ }^{4,21,22)}$ When $\mu=10^{-2} \mathrm{~m} / \mathrm{sK}$ was assumed here for the $\mathrm{Nd}_{2} \mathrm{Fe}_{14} \mathrm{~B}$ phase, the growth velocity of the $\mathrm{Nd}_{2} \mathrm{Fe}_{14} \mathrm{~B}$ phase was higher than that of the Fe phase at the transition temperature of $1459 \mathrm{~K}$, while the growth velocity of the $\mathrm{Fe}$ phase is always higher than that of the $\mathrm{Nd}_{2} \mathrm{Fe}_{14} \mathrm{~B}$ phase in the case of $\mu=10^{-3} \mathrm{~m} / \mathrm{sK}$. From these comparisons, it is suggested that the change in the $\mu$ value results in the selection of different phases. Since it has been reported that the $\mu$ value is $0.014 \mathrm{~m} / \mathrm{sK}$ in a cubic intermetallic compound $\mathrm{FeSi}^{22)}$ here $\mu=10^{-3} \mathrm{~m} / \mathrm{sK}$ may be reasonable for the $\mathrm{Nd}_{2} \mathrm{Fe}_{14} \mathrm{~B}$ phase due to tetragonal intermetallic compound $(c / a=1.39)$. Umeda et $a l .{ }^{17)}$ calculated the transition velocity without considering the kinetic undercooling. In order to determine the value of the transition velocity for the phase selection between $\mathrm{Fe}$ phase and the $\mathrm{Nd}_{2} \mathrm{Fe}_{14} \mathrm{~B}$ phase precisely, it is necessary to take into account the kinetic undercooling, because the growth velocity of the $\mathrm{Nd}_{2} \mathrm{Fe}_{14} \mathrm{~B}$ phase depends on the $\mu$ value.

Splat quenching of the melt undercooled to the temperature just above the nucleation temperature of the $\mathrm{Fe}$ phase was carried out in order for the growth kinetics of the $\mathrm{Nd}_{2} \mathrm{Fe}_{14} \mathrm{~B}$ phase to be facilitated. The $\mathrm{Nd}_{2} \mathrm{Fe}_{14} \mathrm{~B}$ phase solidified directly from the undercooled melt, as shown in
Fig. 7, in contrast with the levitation sample. Moreover, modifying this splat quenching technique, a small magnet of the near-net shape was successively produced by a pair of copper chill plates with hemispherical caps, as shown in Fig. 8(b). The $\mathrm{Nd}_{2} \mathrm{Fe}_{14} \mathrm{~B}$ phase, however, was restricted to within the area adjacent to the edge of the sample. There are two possible reasons why the $\mathrm{Nd}_{2} \mathrm{Fe}_{14} \mathrm{~B}$ phase was not formed at the center of the sample. One is that the voids formed during quenching might suppress the rejection of the latent heat to chill plates. The other is that the cooling rate might not be sufficient for the entire volume of the melt to solidify into the $\mathrm{Nd}_{2} \mathrm{Fe}_{14} \mathrm{~B}$ phase directly.

In order to solve the above-mentioned problems and to increase the volume fraction of the $\mathrm{Nd}_{2} \mathrm{Fe}_{14} \mathrm{~B}$ phase, there are three methods available, quenching at reduced pressure, increase of the initial undercooling prior to quenching, and optimization of the chemical compositions, respectively. The first one is difficult, because electromagnetic levitation is fundamentally unsuited for experiments under reduced pressure, in particular at the pressure level of glow discharge. In high vacuum, on the other hand, it may occur that vaporized elements having high vapor pressure such as $\mathrm{Nd}$ are deposited on the levitation coil and then induce the discharge in the coil. The second one is also difficult, because the thin film formed above the liquidus temperature, as shown in Fig. 5, catalyzes the nucleation of the Fe phase, which reduced the initial undercooling. The main advantage of the combination of the EML and splat quenching is to control the initial undercooling prior to the quenching, in contrast with the melt spinning where the melt is usually quenched from temperatures above the liquidus temperature. The third one is the most effective method, if we can optimize the chemical composition of samples to be undercooled below the peritectic temperature without precipitation of the Fe phase. The alternative method is to use samples that can easily be vitrified.

\section{Conclusions}

Containerless solidification was carried out to elucidate the solidification behavior in the $\mathrm{Nd}_{2} \mathrm{Fe}_{14} \mathrm{~B}$ system. The free surface of the levitated melt allowed us to observe recalescence using the HSV, in contrast with the melt spinning. The $\mathrm{Fe}$ phase solidified primarily and the $\mathrm{Nd}_{2} \mathrm{Fe}_{14} \mathrm{~B}$ phase surrounded the primary $\mathrm{Fe}$ dendrites. When the $\mathrm{Nd}_{2} \mathrm{Fe}_{14} \mathrm{~B}$ phase was formed, the macroscopic interface of the thermal field was clearly observed. From the microstructural observation which showed that the $\mathrm{Nd}_{2} \mathrm{Fe}_{14} \mathrm{~B}$ phases came into contact with each other, it is suggested that many sites for nucleation of the $\mathrm{Nd}_{2} \mathrm{Fe}_{14} \mathrm{~B}$ phase are not be necessary for the successive growth of the $\mathrm{Nd}_{2} \mathrm{Fe}_{14} \mathrm{~B}$ phase that was maintained by the spread of the $\mathrm{Nd}_{2} \mathrm{Fe}_{14} \mathrm{~B}$ phase to the different primary $\mathrm{Fe}$ dendrites. From among the three kinds of formation mechanisms of the peritectic phase, the direct growth of the $\mathrm{Nd}_{2} \mathrm{Fe}_{14} \mathrm{~B}$ phase appears to be responsible for this peritectic formation.

The quenching of the undercooled melt was carried out by combining the EML with the splat quenching system in order to promote the growth kinetics of the $\mathrm{Nd}_{2} \mathrm{Fe}_{14} \mathrm{~B}$ phase. When the melt was quenched prior to nucleation of the primary $\mathrm{Fe}$ 
phase, the $\mathrm{Nd}_{2} \mathrm{Fe}_{14} \mathrm{~B}$ phase solidified directly from the undercooled melt. Moreover, a small magnet with desired shape was successively produced by the copper chill plates with hemispherical holes. This result suggests the possibility of net shaping of the small magnet from the melt.

\section{Acknowledgements}

This work was supported by Japan Space Utilization Promotion Center (JSUP) as part of the R\&D Project of High Performance Magnetic Materials supported by the New Energy and Industrial Technology Development Organization (NEDO) and also supported by Research Fellowships of the Japan Society for the Promotion of Science (JSPS) and JSPS for Young Scientists.

\section{REFERENCES}

1) R. Hermann and W. Loeser: J. Appl. Phys. 83 (1998) 6399-6401.

2) J. J. Croat, J. F. Herbst, R. W. Lee and F. E. Pinkerton: J. Appl. Phys. 55 (1984) 2078-2082.

3) M. Yamamoto, A. Inoue and T. Masumoto: Metall. Trans. 20A (1989) 5-11.

4) S. Hirosawa: Sumitomo Special Metals Co., Japan, private communication, 2001
5) M. Suzuki, T. J. Picone, M. C. Flemings and H. D. Brody: Metall. Trans. 22A (1991) 2761-2768.

6) A. Zambon, B. Badan, K. Eckler, F. Gartner, A. F. Norman, A. L. Greer, D. M. Herlach and E. Ramous: Acta Mater. 46 (1998) 46574670.

7) C. H. Sellers, T. A. Hyde and D. J. Branagan: J. Appl. Phys. 81 (1997) 1351-1357.

8) X. L. Chen, J. K. Liang, S. S. Xie and Z. Y. Qiao: J. Less-Common Met. 159 (1990) 147-152.

9) H. W. Kerr and W. Kurz: Int. Mater. Rev. 41 (1996) 129-164.

10) K. Nagashio, Y. Takamura, K. Kuribayashi and Y. Shiohara: J. Crystal Growth 200 (1999) 118-125.

11) K. Nagashio, K. Kuribayashi and Y. Takamura: Acta Mater. 48 (2000) 3049-3057.

12) D. H. St John and L. M. Hogan: J. Mater. Sci. 17 (1982) 2413-2418.

13) D. H. St John: Acta Metall. Mater. 38 (1990) 631-636.

14) A. Jha and H. A. Davies: J. Non-Cryst. Solids 113 (1989) 185.

15) M. T. Clavaguera-Mora, M. D. Baro, S. Surinach and N. Clavaguera: J. Mater. Res. 5 (1990) 1201-1206.

16) D. J. Branagan and R. W. McCallum: J. Magn. Magn. Mater. 146 (1995) 89-102.

17) T. Umeda, T. Okane and W. Kurz: Acta Mater. 44 (1996) 4209-4216.

18) R. Trivedi and W. Kurz: Int. Mater. Rev. 39 (1994) 49-73.

19) J. Lipton, W. Kurz and R. Trivedi: Acta Metall. 35 (1987) 957-964.

20) J. S. Langer and H. Muler-Krumbhaar: Acta Metall. 26 (1978) 1681.

21) S. R. Coriell and D. Turnbull: Acta Metall. 30 (1982) 2135-2139.

22) D. M. Herlach: Mater. Sci. Eng. A 179/180 (1994) 147-152. 